\title{
Statyba
}

\section{CONSOLIDATION OF DISTURBED AND UNDISTURBED CLAY AND DIFFERENTIAL SETTLEMENT OF BUILDINGS}

\section{A. Alikonis}

To cite this article: A. Alikonis (1999) CONSOLIDATION OF DISTURBED AND UNDISTURBED CLAY AND DIFFERENTIAL SETTLEMENT OF BUILDINGS, Statyba, 5:1, 36-46, DOI:

10.1080/13921525.1999.10531431

To link to this article: https://doi.org/10.1080/13921525.1999.10531431

Published online: 26 Jul 2012.

Submit your article to this journal $₫$

Џ Article views: 120 


\section{КОНСОЛИДАЦИЯ ГЛИНИСТОГО ГРУНТА ЕСТЕСТВЕННОЙ И НАРУШЕННОЙ СТРУКТУРЫ И НЕРАВНОМЕРНЫЕ ОСАДКИ ОСНОВАНИЙ ЗДАНИЙ И СООРУЖЕНИЙ}

\section{А. Аликонис}

\section{1. Введение}

На результаты расчета неравномерных осадок, кроме других факторов, значительное влияние оказывает рост нагрузки, что наблюдается при современном строительстве зданий и сооружений быстрыми темпами [1]. При расчете конструкции на деформируемом основании нарастание осадок во времени обычно не учитывается. Однако, как отмечается в [2], в ряде случаев результаты расчета без учета фактора времени могут приводить к сушественным количественным и качественным ошибкам.

Неравномерные осадки, могущие быть следствием разных скоростей развития осадок отдельных опор конструктивных элементов здания, могут привести $\mathrm{K}$ перенапряжению данного элемента. На это явление оказывает влияние не столько разница в осадках разных точек основания, сколько относительная разность осадок

$$
\Delta s_{u}=\frac{s_{1}-s_{2}}{L},
$$

где $\Delta s_{u}$ - допустимая относительная разность осадок отдельных точек основания; $s_{1}$ и $s_{2}-$ осадки отдельных точек основания; $L$ - расстояние между точками.

Разница осадок $s_{1}$ и $s_{2}(1)$, при которой относительная разность осадок станет недопустимой, может появиться во время строительства здания из-за того, что одна из этих осадок будет происходить с большей скоростью, чем другая. Следовательно, чем болыше скорость развития неравномерных осадок основания, тем реашнее возможность раскрытия трещин в конструктивных элементах здания. Технологические меры ведения строителыных работ с целыо ограничения общей скорости осадки основания не эффективны без одновременного ограничения скорости развития неравномерных осадок. Из выштеизложенного видно, что при основаниях из глинистого грунта нарушенной и ненарушенной структуры или из грунта нарушенной структуры, но разной толщины, что бывает при строительстве на уплотненном глинистом основании, следует провести анализ изменений скоростей развития осадок во времени.

Вопрос анализа развития скоростей неравномерных осадок является актуальным, так как инженерно-геологические условия земельных участков для строительства не всегда бывают хорошими.

Соответствующий учет возможностей неравномерных скоростей развития осадок оснований и их оценка при проектировании помогут избежать послепостроечного ремонта зданий.

Для прогнозирования величины скорости неравномерной осадки следует учитывать особенности фильтрационных свойств грунта, влияние структурной прочности и болыой природной уплотненности на величину начального градиента напора, при котором проявляется фильтрационная консолидация грунта основания.

2. Влияние структурной прочности на начало фиптрационной консолидащии глинистого грунта ненарушенной и нарушенной структуры и на неравномерность осадок зданий и сооружений

Начальная или мгновенная осадка глинистого грунта ненарушенной структуры происходит сразу после загружения грунта. При водонасы- 
щенных грунтах во время начальной осадки вода из пор не вьжимается, деформации являются упругими до тех пор, пока нагрузка не превысит структурной прочности. Эта осадка невелика, и ее пренебрегают [3]. Величину начальной осадки можно зафиксировать при полевых штамповых испытаниях грунта.

Наличие начального градиента напора приводит к тому, что фильтрация в глинистых грунтах не всегда подчиняется закону Дарси [4, 5]. Величина начального градиента зависит от плотности грунтов, содержания глинистой фракщии, ее химико-минералогического состава, концентрации электролитов и температуры воды [4].

Так как величина начального градиента зависит от многих факторов, значения последних колеблются в больших пределах: для $w=32,5-27 \%$, $I_{H}=17-31$ [4], а в [6] приводятся обобшенные значения $I_{H}=12-8$.

Явление начального градиента фильтрации изучалось [7] на образцах глин нарушенной и ненарушенной структуры, в различных диапазонах давлений обжима с испољьованием пресной воды. Полученные данные свидетельствовали о наличии в глинах фильтрационных аномалий, заключающихся в проявлении начального градиента и нарушении линейной зависимости между скоростью фильтрации и градиентом напора. Установлено, что с увеличением давления от 0,1 до 0,6 МПа значения $I_{0}$ возрастают от 2 до 37 .

Средние значения структурной прочности лимноглациальных глин Литвы в зависимости от влажности получены равными от 0,1 до $0,03 \mathrm{MПа}$ [8]. Значит, поровое давление появляется лишь при нагрузках, превышающих указанные значения. Начало появления порового давления при нагрузках, превышаюших структурную прочность грунта, отмечено и другими исследователями [9].

Для исследования фильтрационной консолидации глинистого грунта проводились компрессионные испытания лимноглациальной глины Литвы и рассчитывались коэффициенты фильтрации [10] грунта нарушенной и ненарушенной структуры при разных давлениях и разных значениях натального коэффициента пористости.
Значения коэффициента фильтрации лимноглациальной глины нарушенной и ненарушенной структуры, определенные по результатам компрессионных испытаний, приведены в таблице. Метод расчета коэффициентов фильтрации по опытам, проведенным с компрессионными приборами [10], не является точным, но для сравнительного анализа фильтрационных явлений в глинистом грунте нарушенной и ненарушенной структуры он может быть применен.

Значения коэффициента фильтрации, рассчитанные по результатам компрессионных испытаний (см. таблицу), свидетельствуют о том, что четкой зависимости от действующего давления и начального коэффициента пористости не выявлено. Такой зависимости нет не только для исследованных образцов лимноглациальной глины естественного сложения, но и для образцов нарушенной структуры.

Исследованные глинистые грунты были водонасышены $\left(s_{r}=0.8 \div 1\right)$, поэтому деформации от приложенной нагрузки были возможны лишь при отжатии воды из пор грунта. На сжимаемость глинистого грунта естественного сложения оказывает влияние структурная прочность. Для исследованных глинистых грунтов структурная прочность, определяемая по методике [11], составила от 0,1 до 0,03 МПа [12]. Нарушение структурных связей при разных нагрузках происходит неодинаково. При увеличении нагрузки они разрушаются постепенно. В связи с этим, пока нагрузка не превыпгает структурной прочности, деформация грунта будет присходить только за счет упругого сжатия грунта. Сжатие водонасыщенного грунта происходит, когда разрушаются структурные связи между частищами и создается напор, при котором возможна филтрация воды из грунта [13]. Поэтому и при компрессионных испытаниях нагрузка начала интенсивного сжатия примерно соответствует прочности структурньх связей.

В [16] предлагается структурную прочность глинистого грунта оценивать при помощи начального коэффициента порового давления или величиной порового давления при первых ступенях нагрузки. 
Коэффициенты фильтрации лимноглациальной глины нарушенной и ненарушенной структуры

Coefficient of permeability of limnoglacial clay with disturbed and undisturbed structure

\begin{tabular}{|c|c|c|c|c|c|}
\hline \multicolumn{3}{|c|}{ Ненарушенная структура } & \multicolumn{3}{|c|}{ Нарушенная структура } \\
\hline $\begin{array}{c}\text { Нагрузка } \sigma, \\
\text { МПа }\end{array}$ & $\begin{array}{c}\text { Начальный } \\
\text { коэффициент } \\
\text { пористости, } e\end{array}$ & $\begin{array}{c}\text { Коэффициент } \\
\text { фильтрации, } \\
\text { см/сек }\end{array}$ & $\begin{array}{c}\text { Нагрузка } \\
\sigma, \text { МПа }\end{array}$ & $\begin{array}{c}\text { Начальный } \\
\text { коэффициент } \\
\text { пористости, } e\end{array}$ & $\begin{array}{c}\text { Коэффициент } \\
\text { фильтрации, } \\
\text { см/сек }\end{array}$ \\
\hline 0.05 & $\begin{array}{l}1.000-0.900 \\
0.900-0.800 \\
0.800-0.700 \\
0.700-0.600 \\
0.600-0.500\end{array}$ & $\begin{array}{l}- \\
- \\
- \\
- \\
-\end{array}$ & 0.05 & $\begin{array}{l}1.000-0.900 \\
0.900-0.800 \\
0.800-0.700 \\
0.700-0.600 \\
0.600-0.500\end{array}$ & $\begin{array}{c}- \\
1 \times 10^{-8}-2 \times 10^{-7} \\
5 \times 10^{-8} \\
- \\
3 \times 10^{-8}\end{array}$ \\
\hline 0.1 & $\begin{array}{l}1.000-0.900 \\
0.900-0.800 \\
0.800-0.700 \\
0.700-0.600\end{array}$ & $\begin{array}{r}1 \times 10^{-8}-2 \times 10^{-9} \\
2 \times 10^{-8} \\
1 \times 10^{-8}-7 \times 10^{-8} \\
7 \times 10^{-8}-1 \times 10^{-7}\end{array}$ & 0.1 & $\begin{array}{l}1.000-0.900 \\
0.900-0.800 \\
0.800-0.700 \\
0.700-0.600 \\
0.600-0.500 \\
\end{array}$ & $\begin{array}{c}- \\
1 \times 10^{-7}-4 \times 10^{-8} \\
4 \times 10^{-9}-6 \times 10^{-9} \\
- \\
4 \times 10^{-8}\end{array}$ \\
\hline 0.2 & $\begin{array}{l}1.000-0.900 \\
0.900-0.800 \\
0.800-0.700 \\
0.700-0.600 \\
0.600-0.500\end{array}$ & $\begin{array}{r}1 \times 10^{-8}-1 \times 10^{-8} \\
2 \times 10^{-8} \\
8 \times 10^{-8} \\
2 \times 10^{-7}-7 \times 10^{-8} \\
-\end{array}$ & 0.2 & $\begin{array}{l}1.000-0.900 \\
0.900-0.800 \\
0.800-0.700 \\
0.700-0.600 \\
0.600-0.500\end{array}$ & $\begin{array}{c}- \\
5 \times 10^{-8}-6 \times 10^{-8} \\
6 \times 10^{-9} \\
- \\
5 \times 10^{-8}\end{array}$ \\
\hline 0.3 & $\begin{array}{l}1.000-0.900 \\
0.900-0.800\end{array}$ & $\begin{array}{l}3 \times 10^{-9} \\
3 \times 10^{-8}\end{array}$ & & & \\
\hline 0.4 & $\begin{array}{l}1.000-0.900 \\
0.900-0.800\end{array}$ & $\begin{array}{l}5 \times 10^{-9} \\
3 \times 10^{-9}\end{array}$ & & & \\
\hline
\end{tabular}

$$
\sigma_{c m p}=\sigma\left(1-\beta_{0}\right)
$$

где $\sigma$ - величина действующей нагрузки; $\beta_{0}-$ коэффициент порового давления.

$$
\beta_{0}=\frac{u}{\sigma}=\frac{\sigma-\sigma_{c m p}}{\sigma} .
$$

Из формул (2) и (3) видно, что пока действующая нагрузка не превышает структурной прочности грунта, величина порового давления близка к нулю.

Из вышеизложенного следует, что отсутствие цанных расчета коэффициента фильтрации по результатам компрессионных испытаний глинистого грунта при малых нагрузках $(0.05$ и $0.1 \mathrm{MПа,}$ см. таблицу) связано со структурной прочностью грунта и отсутствием напора, вызываюшего фильтрацию воды из пор водонасыщенного грунта.
По-другому происходит сжатие глинистого грунта нарушенной структуры. В этом случае первая ступень нагрузки почти не встречает сопротивления со стороны структурной прочности и давление передается на скелет и поровую воду грунта.

Если нагрузка создает напор, при котором начинается фиљтрация воды, происходит сжатие грунта. По данным экспериментальных исследований лимноглациаљных глин нарушенной структуры уже при нагрузке $0.05 \mathrm{MПа} \mathrm{в} \mathrm{образцах,}$ испытанных В компрессионном приборе, создавались напоры, вызывающие фильтрацию поровой воды (см. таблицу).

На рис. 1 показан характер распределения приблизительных осредненных значений коэффициентов фильтрации озерноледниковой глины нарушенной и ненарушенной структуры, полу- 
ченных по результатам компрессионных испытаний в зависимости от начатьного коэффициента пористости и нагрузки. Эксперименты проводились с лимноглациальной глиной микрослоистой текстуры, влажность которой составляла от 18 до $36 \%$, коэффициент пористости - от 0.560 до 1.010 , коэффициент водонасышенности $s_{r}=0.8-1$.

Из анализа данных таблицы и рис. 1 следует, что глинистый грунт нарушенной структуры деформируется с момента приложения нагрузки, менышей чем структурная прочность грунта, а деформации в основном носят характер фильтрационной консолидации. Исследованный лимноглациальный глинистый грунт ненарушенной структуры при нагрузках, не превышающих структурной прочности, сжимается за счет упругих деформаций скелета, а при нагрузках, превышагщих структурную прочность, начинаются деформации фильтрационной консолидации. Деформации за счет ползучести скелета грунта составляют неболышую долю от общей деформации. Следует предполагать, что при сжатии глинистого грунта нарушенной структуры первая ступень нагрузки соответствует началу фильтрационной консолидации. Она создает напор в поровой воде, который соответствует начальному градиенту.

В глинистом грунте ненарушенной структуры начальный градиент достигается после постепенного нарушения структурных связей между частицами и агрегатами грунта.

Анализируя компрессионную сжимаемость лимноглациальных глин нарушенной и ненарушенной структуры [15] и результаты фиљтрационных расчетов (см. таблицу, рис. 1), можно заметить, что лимноглациалыный глинистый грунт нарушенной структуры в основаниях зданий и сооружений будет деформироваться гораздо больше и быстрее во времени по сравнению с грунтом ненарушенной структуры. В случае залегания в основании здания глинистого грунта ненарушенной или нарушенной структуры, хотя и уплотненного до естественной плотности, могут появляться неравномерные осадки строящихся зданий.

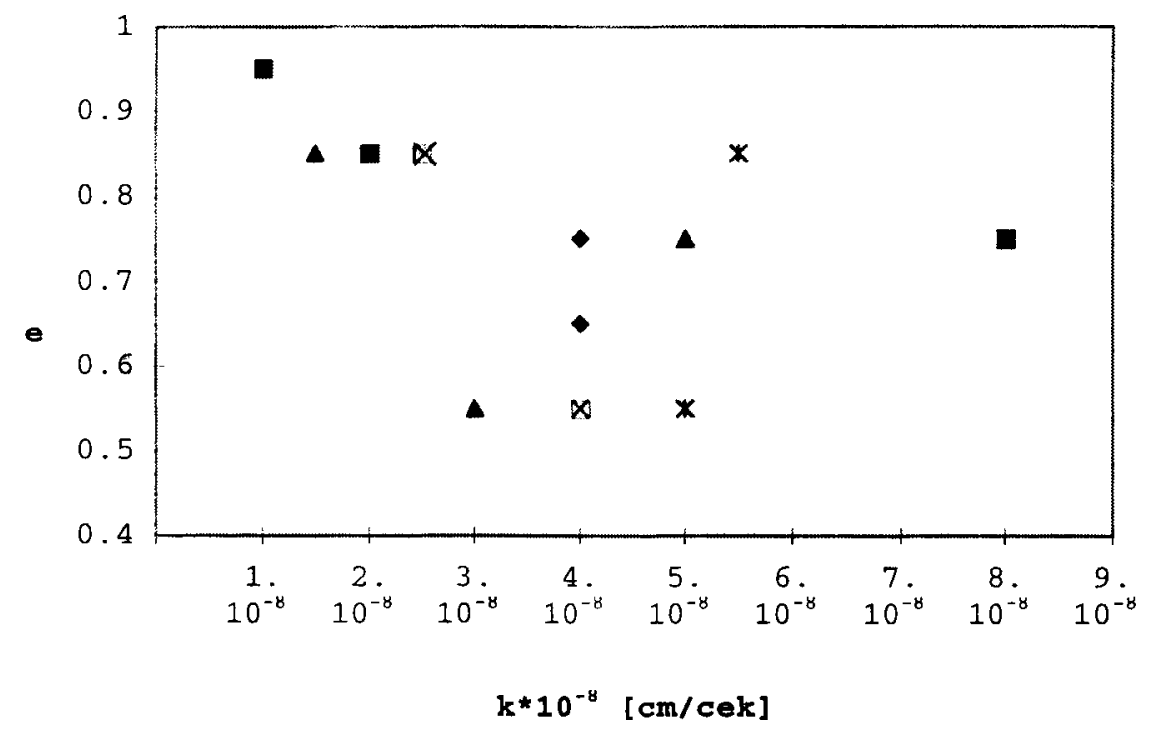

Рис. 1. Приблизительные осредненные значения коэффициентов фильтрации лимноглациальной глины. Ненарушенная структура: - $-0.1 \mathrm{MПа,} \mathrm{-} \sigma=0.2$ МПа.

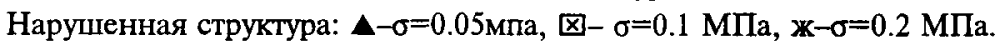

Fig 1. Mean values of coefficient of permeability of limnoglacial clay. Undisturbed structure: $-\sigma=0.1 \mathrm{MPa}, \boldsymbol{\nabla}-\sigma=0.2 \mathrm{MPa}$. Disturbed structure: $\wedge-\sigma=0.05 \mathrm{Mpa}$, 囚 $\sigma=0.1 \mathrm{MPa}, \mathbf{x}-\sigma=0.2 \mathrm{MPa}$ 
Одной из причин неравномерных осадок является разное время протекания осадок грунта во времени. В практике строительства это случается, когда, например, один фундамент опирается на глинистый грунт ненарушенной структуры, а другой - на слой глинистого грунта нарушенной структуры, хотя и уплотненного до естественной плотности. Осадка фундамента на естественном грунте будет происходить медленно, а при большой структурной прочности даже некоторое время при соответствующей нагрузке осадки могут и отсутствовать. В то же время осадка фундамента на глинистом грунте нарушенной структуры будет происходить с момента приложения нагрузки и с большой скоростью.

В этом случае может наступить такой момент времени, когда относительная разность осадок превысит предельно допустимую для данной конструкщии здания. Появятся трещины, хотя прогнозируемые стабилизированные осадки и относительная разность стабилизированных осадок не превышают допустимых значений.

\section{3. Тощщина сжимаемой зоны грунта и скорости} протекания осадки основания здания во времени

Время протекания осадки, кроме вышеуказанных факторов, зависит также от толщины зоны деформируемости в основании зданий и сооружений. В зависимости от соотношения напряженного состояния грунта $\left(\sigma_{z}\right)$, величины структурной прочности $\left(\sigma_{c m p}\right)$ и давления, определяющего начало фильтрации $\left(\sigma_{I H}\right)$, в основании здания или сооружения формируются зоны деформации. Р. Э. Дашко и А. А. Коган [13] выделяют четыре варианта возникновения зон деформации в зависимости от соотношения $\sigma_{z}$, $\sigma_{c m p}$ и $\sigma_{I H}$ :

1. $\sigma_{z}>\sigma_{c m p}>\sigma_{I H}$. В этом случае в первой зоне уплотнение происходи $\mathrm{T}$ за счет фильтрационной и ползучей консолидации, а в третьей (нижней) - только за счет упругого сжатия.

2. $\sigma_{z}>\sigma_{I H}>\sigma_{c m p}$. В этом слугае в первой (верхней) зоне уплотнение происходит аналогично первому случаю. Во второй (средней) зоне, где $\sigma_{z}<\sigma_{I H}>\sigma_{c m p}$, уплотнение происходит только за счет ползучести, а в третьей (нижней) зоне $\left(\sigma_{z}<\sigma_{c m p}\right)$ будет упругое сжатие.

3. $\sigma_{z}=\sigma_{I H}>\sigma_{c m p}$. В этом случае отсутствует зона фильтрационного уплотнения. В третьей зоне при $\sigma_{z}<\sigma_{c m p}$ отмечается зона упругого сжатия грунта.

4. $\sigma_{z}<\sigma_{c m p}$. В этом случае уплотнения грунта не происходит, будет только упругое сжатие.

Если пренебречь уплотнением грунта упругого характера, что можно сделать в начальной стадии сжатия $[3,14]$, на расчет скорости развития осадок во времени в основном будет оказывать влияние только фиљтрационная консолидация.

Рассмотренные выше особенности деформирования глинистых грунтов дают возможность составить расчетные схемы для определения сжимаемой зоны основания для глинистого грунта ненарушенной и нарушенной структуры.

Принимая, что глинистый грунт нарушенной структуры не имеет структурной прочности, а приложенная нагрузка превышает начальный градиент фильтрационного уплотнения, что характерно для исследованной тимноглациальной глины (см. таблицу), получим расчетную схему зоны фильтрационной консолидации, представленной на рис. 2.

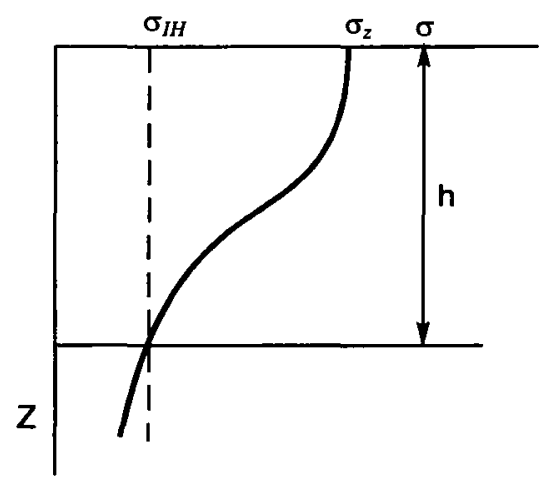

Рис. 2. Зона фильтрационной консолидации глинистого грунта нарушенной структуры в основании здания

Fig 2. Depth of consolidation zone under the foundation

В глинистом грунте ненарушенной структуры при нагрузках, не превышающих структурной прочности, не будет формироваться зона фильтрационной консолидации в основании здания, 


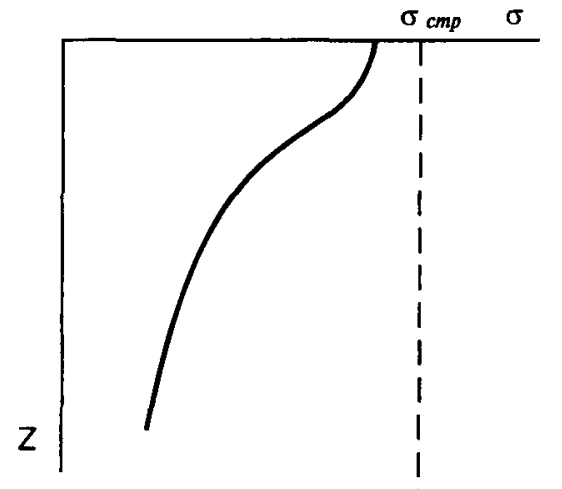

Рис. 3. Расчетная схема сжимаемой зоны глинистого грунта ненарушенной структуры в основании здания при $\sigma_{z}<\sigma_{c m p}$

Fig 3. Compression zone of undisturbed clay under stress $\sigma_{z}<\sigma_{s}$

что замечено в исследованной лимноглациальной глине (см. таблицу).

Расчетная схема сжимасмой зоны для глинистого грунта ненарушенной структуры при нагрузке, не превышаюшей структурной прочности грунта, представлена на рис. 3.

Из рис. 3 видно, что при $\sigma_{z}<\sigma_{c m p}$ уплотнения грунта не произойдет. Если в плане здания основание состоит из глинистого грунта нарушенной и ненарушенной структуры, то при нагрузках, не превышаюших структурной прочности естественного грунта, возникнут разные скорости осадки, приводящие к неравномерным осадкам и недопустимой относительной разности осадок основания. Например, для исследованной лимноглациальной глины нарушенной структуры $\left(e_{1}=1,000-0,900\right)$ при нагрузке $0.1 \mathrm{MПа,} \mathrm{размерах}$ фундамента $b \times 1=2 \times 2 \mathrm{M}, k=0.24 \mathrm{~cm} /$ год, $v=0.4$ по методике Н. А. Цытовича [14] получим следуюшие данные для построения кривой затухания осадок основания во времени: $s_{1.25}=2.7 \mathrm{cM}, s_{) .5}=2.8$ $\mathrm{cM}, s_{1}=3.2 \mathrm{~cm}, s_{5}=5.6 \mathrm{~cm}, s=6.3 \mathrm{~cm}$. Кривая 1 , построенная по этим данным, показана на рис. 4 .

Анализ зависимостей осадки от времени (рис. 4) показывает, что если рядом на расстоянии 6 м находится фундамент на естественном глинистом грунте и давление $p=0.1$ МПа на него не превышает структурной прочности, то он будет иметь недопустимую для соответствующих зданий [16] относительную разницу осадок

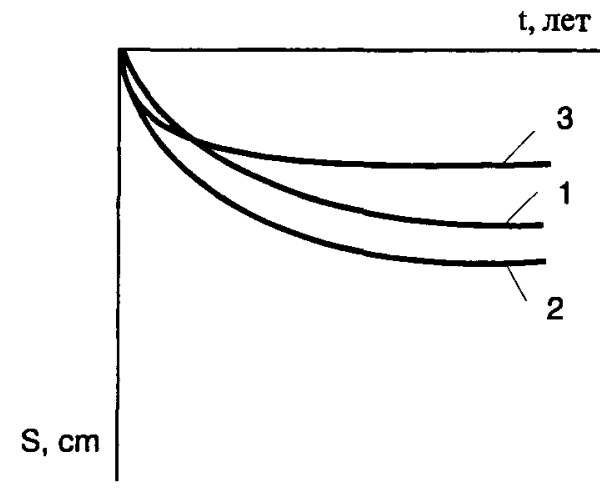

Рис. 4. Кривые затухания осадок основания, сложенного из глины нарушенной и ненарушенной структуры, во времени: 1 - нарушенная структура $p=0.1 \mathrm{MПа;}$ 2 - то же $p=0.2 \mathrm{MПа;} 3$ - ненарушенная структура $p=0.2 \mathrm{M \Pi а}$

Fig 4. Time-settlement relationships of clays with disturbed and undisturbed structure; 1 - disturbed structure, $p=0.1 \mathrm{MPa} ; 2$ - disturbed structure, $p=0.2$ $\mathrm{MPa} ; 3$ - undisturbed structure, $p=0.2 \mathrm{MPa}$

$\Delta s / L=0.004-0.01$. Недопустимая относительная разность осадок наступит не сразу после приложения нагрузки, а спустя какое-то время, например, при $t=1$ год $\Delta s / L=0.006$.

Такой случай может иметь место на начальной стадии ведения строительных работ. При увеличении нагрузки по линейной зависимости до проектной скорости затухания осадок основания из глины нарушенной и ненарушенной структуры будут разными. Если, например, относительная разность осадок, полученная из расчета стабилизированных осадок фундаментов, не превышает допустимого значения, то из-за разной скорости развития осадок во времени при предыцуцих нагрузках может иметь место момент, когда относительная разность осадок будет больше предельно допустимой, и в конструкщиях здания появятся трещины. Осадки глинистого основания ненарушенной структуры будут развиваться медленнее по сравнению с глиной нарушенной структуры, так как нужная величина начального градиента напора будет достигнута не сразу, а по мере преодоления структурной прочности грунта.

По методике расчета эквивалентного слоя грунта Н. А. Цытовича [14] с учетом оценки структурной прочности грунта (рис. 5) осадка фундамента $b \times 1=2 \times 2$ м при $m_{v}=0,022, v=0,4$, 
$k=0,24 \quad$ см/год, $\quad p=0,2 \quad$ МПа $\quad\left(a_{1}=1,000-0,900\right)$ составляет $6,8 \mathrm{~cm}$, а для основания нарушенной структуры при $m_{v}=0,036, v=0,4, k=0,24$ см/год $11 \mathrm{cм}$. Относительная разность осадок составляет $\Delta s / L \approx 0,006$, что не превышает предельно допустимого значения [16] для соответствуюших зданий.

Кривые затухания осадок основания ненарушенной и нарушенной структуры, построенные по методике [14], показаны на рис. 4. Из представленных на рис. 4 кривых затухания осадок основания во времени видим, что относительная разность осадок достигает наибольшего значения спустя некоторое время после приложения нагрузки на основание.

Неравномерные осадки оснований во времени могут наблюдаться и при строительстве на уплотненном глинистом грунте нарушенной структуры разной толщины. В таком случае расчет нарастания осадок во времени удобнее вести по эквивалентному методу расчета осадок для слоистого основания Н. А. Цытовича [17] с учетом оценки структурной прочности естественного глинистого грунта.

\section{4. Прогноз скорости осадки глинистого грунта} нарушенной структуры в основании здания по компрессионной кривой того же грунта ненарушенной структуры

Для расчета развития осадки основания во времени согласно теории фильтрационной консолидации (Терцаги-Герсеванова-Флорина и др.) требуется определить вспомогательные показатели $C_{v}$ и $N$.

$$
\begin{aligned}
& C_{v}=\frac{k}{\gamma_{w} m_{v}}, \\
& N=\frac{\pi^{2} C_{v}}{4 h^{2}} t,
\end{aligned}
$$

где $k$ - коэффициент фильтрации водонасыщенного грунта при выдавливании внешней нагрузкой воды из его пор; $\gamma_{w}$ - удельный вес поровой воды $\left(10 \mathrm{kH} / \mathrm{M}^{3}\right) ; m_{v}-$ коэффициент относительной сжимаемости грунта; $h$ - глубина активной зоны сжатия под фундаментом; $t$ момент времени от начала загружения грунта.

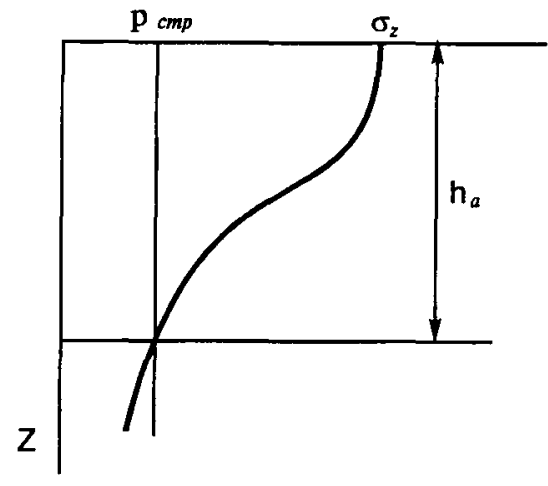

Рис. 5. Расчетная схема сжимаемой зоны глинистого грунта ненарушенной структуры при $\sigma_{z}>\sigma_{c m p}$

Fig 5. Compression zone of undisturbed clay under stress $\sigma_{z}>\sigma_{s}$

Коэффициенты фильтрации по результатам компрессионных исследований, например, лимноглациаљьнй глины Литвы (см. таблицу) нарушенной и ненарушенной структуры резко не различаются. Поэтому при предварительных расчетах прогнозирования протекания во времени осадки основания нарушенной и ненарушенной структуры можно принять одинаковое значение коэффициента фильтрации.

Глубина активной зоны сжатия $h$ (5) под фундаментом для грунта нарушенной структуры при расчете протекания осадок во времени по методу расчета эквивалентного слоя Н. А. Цытовича $[14,17]$ определяется по формуле:

$$
h=2 h_{3} \text {, }
$$

где $h_{\ni}$ - мощность эквивалентного слоя грунта $[14,17]$.

Глубина активной зоны сжатия $h$ (5) под фундаментом для грунта ненарушенной структуры при расчете протекания осадок во времени по методу эквивалентного слоя Н. А. Цытовича [14, 17] определяется по формуле:

$$
h_{a}=2 h_{\ni}\left(p-p_{s}\right) / p,
$$

где $p$ - давление по подошве фундамента; $p_{s}$ структурная прочность грунта.

Стабилизированная осадка с учетом структурной прочности грунта по методу эквивалентного слоя вычисляется по формуле: 


$$
s=\frac{h_{a}}{2} m_{\nu}\left(p-p_{s}\right),
$$

где $m_{v}$ - коэффициент относительной сжимаемости грунта.

Для расчета протекания осадки основания нарушенной структуры во времени можно принять уплотняющее давление, убывающее с глубиной по закону треугольника, что соответствует большому числу случаев уплотнения грунта под действием нагрузки от фундаментов сооружений.

Таким образом, при односторонней фильтрации воды (вверх) для любого времени $t$ осадка фундамента будет:

$$
\begin{aligned}
s_{t}= & h_{\ni} m_{\nu} p \times \\
& \times\left\{1-\frac{16}{\pi}\left[\left(1-\frac{2}{\pi}\right) e^{-N}+\frac{1}{9}\left(1+\frac{2}{3 \pi}\right) e^{-9 N}+\ldots\right]\right\} .
\end{aligned}
$$

После математических преобразований получим

$s_{t}=h_{3} m_{\nu} p\left[1-1.62\left(0.363 e^{-N}+\frac{1}{9} 1.212 e^{-9 N}\right)\right]$.

Для приближенного расчета можно ограничиться первым членом ряда в круглых скобках [14]:

$$
s_{t}=h_{3} m_{v} p\left[1-1.62\left(0.363 e^{-N}\right)\right]
$$

Приблизительная осадка однородного грунта основания

$$
s=h_{9} m_{v} p
$$

По формулам (11) и (12) получим:

$$
s_{t}=s\left[1-1.62\left(0.363 e^{-N}\right)\right] \text {. }
$$

Из формул (4), (5), (12), (13) видим, что для любого времени $t$ от начала приложения нагрузки осадка грунта основания, кроме других факторов, в основном зависит от коэффициента относительной сжимаемости грунта $m_{v}$.

Как правило, при инженерно-геологических исследованиях испытанию подвергается грунт ненарушенной структуры. Если в пределах плана здания предусмотрено использовать глинистый грунт нарушенной структуры (заполнение переборов и др.), то для прогнозирования протекания во времени неравномерных осадок здания следует знать коэффициент относительной сжимаемости $m_{v}$ грунта нарушенной структуры.

Для этой цели можно воспользоваться компрессионной кривой в полулогарифмической системе координат (рис. 6).

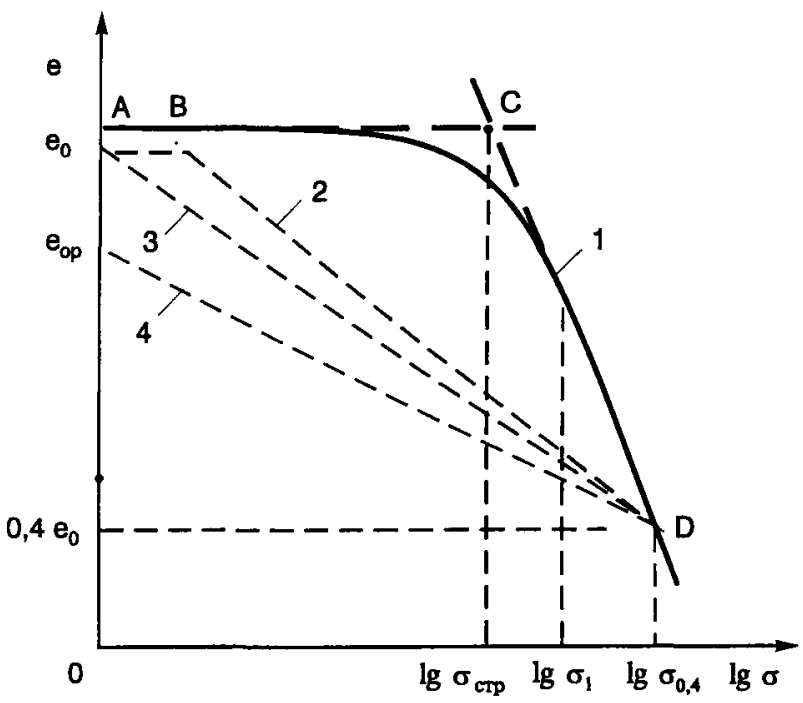

Рис. 6. Компрессионная кривая глинистого грунта, обладающего структурной прочностью в полулогарифмической системе координат: 1 - естественный грунт; 2, 3, 4 - тот же грунт нарушенной структуры (перемят)

Fig 6. Compression curve of clay in semilogarithmic scale; 1 - with undisturbed structure; $2,3,4$ - with disturbed structure

На рис. 6 принято, что грунт нарушенной структуры теряет структурную прочность, так как она (линия $\mathrm{AB}$ ) по сравнению с естественным грунтом очень мала, а графики зависимости $e=f(\lg \sigma)$ соприкасаются при достижении точки $e=0.4 e_{0}[18]$.

По компрессионным кривым (рис. 6) определяем коэффициенты компрессии $C_{c}$ грунта ненарушенной и нарушенной структуры $C_{c}^{\prime}$.

$$
\begin{gathered}
C_{c}=\frac{e_{i}-e_{i+1}}{\lg \sigma_{i+1}-\lg \sigma_{i}}, \\
C_{c}^{\prime}=\frac{e_{0}-e_{0.4}}{\lg \sigma_{0.4}},
\end{gathered}
$$

где $e_{0}-$ начальный коэффициент пористости.

$$
\lg \sigma_{0.4}=\frac{C_{c} \lg \sigma_{C T P}+e_{0}-e_{0.4}}{C_{c}}
$$


Пользуясь коэффициентом компрессии грунта нарушенной структуры $C_{c}^{\prime}$, определяем прогнозируемую осадку слоя грунта $H$ [18] от нагрузки $\sigma_{1}$ :

$$
s=\underset{\jmath}{H} \frac{C_{c}^{\prime}}{1+e_{0}} \lg \sigma_{1} .
$$

Коэффициент относительной сжимаемости грунта нарушенной структуры определяем по формуле:

$$
m_{v}=\frac{s}{H \sigma_{1}} .
$$

Расчет коэффициента относительной сжимаемости $m_{v}$ пाо формулам (17) и (18) можно провести, принимая толщину слоя $H=1$.

По данным расчета относительной сжимаемости $m_{v}$ для данной величины напряжения в плоскости основания фундамента $\sigma_{1}$ определяем вспомогательные показатели (4) и (5) и по формуле (13) получим осадку основания фундамента для любого времени $t$ от момента приложения данной нагрузки.

Вышеуказанная методика для определения относительного коэффициента сжимаемости глинистого грунта нарушенной структуры по компрессионной кривой того же грунта ненарушенной структуры проверялась по результатам компрессионных испытаний лимноглациальной глины [12].

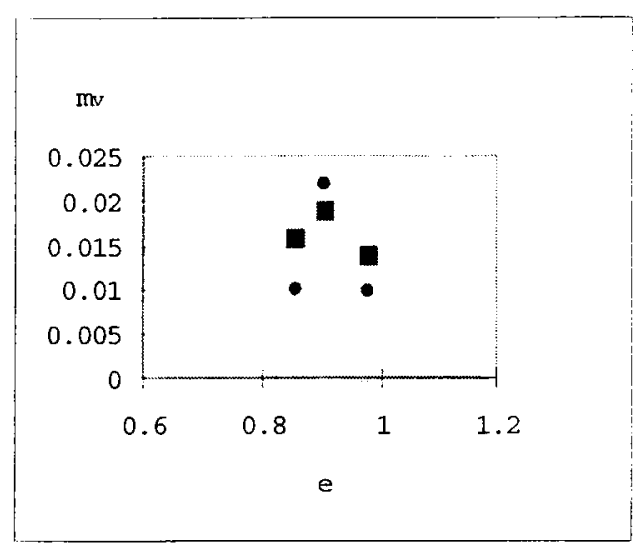

Рис. 7. Коэффициенты относительной сжимаемости при $\sigma=0.2 \mathrm{MПа.} \bullet-$ глина нарушенной структуры; глина ненарушенной структуры

Fig 7. Values of the coefficient of volume compatibility under vertical stress $\sigma=0.2 \mathrm{MPa}$. $\bullet$ - clay with disturbed structure; - clay with undisturbed structure
Результаты сравнения экспериментальных и расчетных значений $m_{v}$ представлены на рис. 7.

Сравнение экспериментальных и расчетных результатов (рис. 7) показало удовлетворительную для прогнозирования протекания осадки во времени сходимость экспериментальных и расчетных значений коэффициента относительной сжимаемости.

В том случае, когда контроль уплотнения глинистого грунта нарушенной структуры проводится статическим зондированием, коэффициент относительной сжимаемости $m_{v}$ можно определить косвенным способом, через модуль деформации:

$$
E=\alpha q_{c},
$$

где $\alpha$ - коэффициент перехода; $q_{c}$ - сопротивление погружению конуса.

Так как модуль деформации

$$
E=\frac{\beta}{m_{v}},
$$

где $\beta$ - коэффициент, зависяший от коэффициента поперечной деформации грунта, можно рассчитать коэффициент относительной сжимаемости:

$$
m_{v}=\frac{\beta}{E} .
$$

Достоверность значений коэффициента относительной сжимаемости, полученных по результатам статического зондирования, во многом зависит от точности эмпирического коэффициента $\alpha$ (19) перехода от сопротивления грунта погружению конуса к модулю деформации.

\section{5. Заключение}

Скорость протекания осадки основания здания во времени влияет на развитие его неравномерных осадок. Экспериментальные и теоретические исследования показывают, что при одинаковой нагрузке быстрее во времени протекают осадки грунта нарушенной структуры по сравнению с грунтом ненарушенной структуры. По этой причине при нарастании нагрузки на основание, сложенное из грунта нарушенной и ненарушенной структуры, может наступить момент, 
когда относительная разность осадок станет больше допустимой и в конструкциях здания появятся трещины.

Для прогнозирования возможных неравномерньх осадок и скорости их протекания во времени можно использовать компрессионные зависимости коэффициента пористости от нагрузки.

Принимая, что глинистый грунт нарушенной структуры теряет структурную прочность, по компрессионной кривой естественного грунта в полулогарифмической системе координат можно определить данные для приблизительного расчета осадки во времени грунта нарушенной структуры. Неодинаковая скорость фильтрационной консолидации глинистого грунта нарушенной структуры разной толщины в пределах плана здания также может привести к неравномерным осадкам здания и появлению трещин в конструкциях здания еще во время строительства.

Данные сжимаемости грунта, необходимые для расчета скорости осадки фильтрационной консолидации, можно получить косвенным способом по результатам исследования грунта статическим зондированием.

\section{Литература}

1. Ю. В. Россихин, А. Г. Битайнис. Осадки строящихся сооружений. Рига: Зинатне, 1980. 338 с.

2. ГК по ГС и А при Госстрое СССР. Расчет крупнопанельных зданий на неравномерные осадки основания. М., 1969.66 с.

3. С. Г. Кушнер. Расчет осадок оснований зданий и сооружений. Киев: Будивэльник, 1990. 146 с.

4. Р. Э. Дашко, А. А. Коган. Механика грунтов в инженерно-геологической практике. М.: Недра, 1977. $240 \mathrm{c}$

5. N. Ždankus. Molinił ir durpinių gruntų vandens laidumo ypatumy ivertinimas filtraciniuose tyrimuose ir skaičiavimuose. Kaunas: Technologija, 1995. 106 p.

6. A. Kezdi. Handbuch der Bodenmechanik. Band 1. Berlin: VEB Verlag für Bauwesen, 1969. 134 S.

7. В. М. Гольдберг, Н. П. Скворцов. Проницаемость и фильтрация в глинах. М.: Недра, 1986. 161 с.

8. A. Alikonis ir kt. Lietuvos TSR grunty statybinès savybès. Vilnius: Mintis, $1973.90 \mathrm{p}$.

9. H. Akagi, K. Komija. Constant rate of strain consolidation properties of clayey soil at high temperature. Compression and consolidation of clayey soils // Preceedings of the international symposium an compression and consolidation of clayey soils. IsHiroshima. 1995/ Japan/10-12 May. Vol 1, p. 3-8.

10. Е. Г. Чаповский. Лабораторные работы по грунтоведению и механике грунтов. М.: Недра, 1966. 304 с.
11. Н. А. Цытович. Механика грунтов. М.: Высшая шгкола. 1983. $286 \mathrm{c}$.

12. А. Аликонис. $\mathrm{K}$ вопросу определения структурной прочности глинистого грунта // Научн. тр. вузов ЛитССР. Строит. мат-лы и констр., Т. 3. Вып. 13. Вильнюс: Мокслас, 1974, с. 11-15.

13. Р. Э. Дашко, А. А. Коган. Изменение характера деформируемости водонасыщенньх глинистьх пород в основании сооружений // Прибалтийская геотехника. Каунас, 1968, с. 84-90.

14. Н. А. Цытович. Инженерный метод прогноза осадок фундаментов. М.: Стройиздат, 1988. 121 с.

15. А. Аликонис, А. Жедялис. Особенности осадконакопления и их влияние на деформационные свойства лимноглациальньг глин нарушенного и ненарушенного сложения // Инженерные изыскания для строительства: Материалы семинара изыскателей Прибалтики. Вильнюс: Мокслас, 1975, c. $46-55$.

16. СНиП 2.02.01-83. Основания зданий и сооружений. М.: Стройиздат, 1985. $41 \mathrm{c}$.

17. Н. А. Цытович и др. Прогноз скорости осадок оснований сооружений. М.: Стройиздат, 1967. $239 \mathrm{c}$.

18. Д. А. Леонардас. Основания и фундаменты (перевод с английского). М.: Стройиздат, 1968. 504 с.

Iteikta 19980504

\section{SUARDYTOS IR NESUARDYTOS STRUKTŪROS MOLINIO GRUNTO KONSOLIDACLJA IR PASTATY PAGRINDŲ NEVIENODI NUOSÉDŽIAI}

\section{A. Alikonis}

Santrauka

Dèl pastatu pagrindụ nevienodụ nuosèdžių pastato konstrukcijose atsiranda plyšių. Tačiau pasitaiko, kad plyšiai pastato konstrukcijose atsiranda dèl nevienodu nuosédžiu greičių. Didžiausi nuosèdžių greičiai būna vykstant pagrindo grunto filtracinei konsolidacijai. Jie ir turètụ būti pirmiausia ivertinti apskaičiuojant galimus nevienodus pastato atskiry dalių nuosèdžius.

Eksperimentiniai ir teoriniai tyrimai rodo, kad pastato pagrindo iš suardytos sandaros molinio grunto nuosèdžį̣ greitis yra didesnis už pagrindo iš nesuardytos sandaros grunto. Nuosedžiu greičiai suardytos sandaros grunte yra didesni todèl, kad struktūriniai ryšiai nesipriešina apkrovai, atsiranda porinis slegis ir prasideda grunty filtracine konsolidacija. Nesuardytos struktūros moliniuose gruntuose filtracine konsolidacija prasideda po to, kai jtempimai grunte suardo struktūrinius ryšius, t. y. kai apkrova ị gruntą viršija jo struktūrinị stiprumą. Struktūriniai ryšiai suyra pamažu, todel del filtracinès konsolidacijos atsirandantys pagrindo nuosèdžiai turi mažą greiti.

Jeigu pastato plano ribose yra suardytos struktūros molinis gruntas, nors ir sutankintas iki natūralaus to paties grunto tankumo, dèl skirtingu nuosèdžiu greičių, kaip rodo tyrimai, gali pasitaikyti neleistinas santykinis nuosèdžiy skirtumas.

Suardytos struktūros molinio grunto filtracinès konsolidacijos nuosèdžiu greičiui prognozuoti reikalingus rodiklius galima apskaičiuoti pagal nesuardytos struktüros to paties grunto kompresinę kreivę pusiaulogaritminiu maste- 
liu. Tai daroma laikant, kad suardytos sandaros molinis gruntas yra be struktūrinių ryšių tarp atskirų dalelių.

Kaip rodo atlikti tyrimai, minèta metodika gali būti taikoma apytiksliam pastatụ pagrindų filtracinés konsolidacijos nuosèdžiu prognozavimui.

\section{CONSOLIDATION OF DISTURBED AND UNDISTURBED CLAY AND DIFFERENTIAL SETTLEMENT OF BUILDINGS}

\section{A. Alikonis}

S u m m a r y

Differential settlement of foundations stimulates the development of cracks in structures. However different rate of settlements could be the reason of cracks. The highest rate of settlement takes place during the consolidation period. Theoretical calculations and experimental data showed that rate of settlement of disturbed soil is higher in comparison with undisturbed soil. During the loading of undisturbed soil with structural links displacement of particles and pore pressure dissipation are slower. Pore pressure dissipation begins only after the structural links are broken, ie after the additional stress becomes higher than preconsolidation pressure. The process of disintegration of structural links is slow, therefore the rate of consolidation settlement is also slow. If there are zones of disturbed clay within the layout of building, differential settlement of building can occur. Parameters which are necessary for estimation of the primary consolidation rate of disturbed soil could be calculated using compression curve of the same soil drawn in the semi-logarithmic scale. According to the results of investigations the method described above could be used to predict the rate of primary consolidation of foundations.

Antanas ALIKONIS. Doctor, Associate Professor. Department of Geotechnics. Vilnius Gediminas Technical University. Sauletekio al. 11, 2040 Vilnius, Lithuania Doctor (1968, technical sciences), Associate Professor at the Department of Foundation Engineering. During 1980-96 Head of that Department (now Department of Geotechnics). Research visits to Moscow and Dnepropetrovsk.

Author and co-author of 3 monographs, over 100 scientific articles, 2 patents, 5 inventions and 14 study guides. Research interests: physical and mechanical properties of soils. 